\title{
A qualitative study of local perspectives on problem drinking in Peruvian Andean highlands: control, power, and responsibility
}

Sakiko Yamaguchi ( $\sim$ sakiko.yamaguchi@mail.mcgill.ca )

McGill University Department of Psychiatry https://orcid.org/0000-0003-1905-3244

Raphael Lencucha

McGill University Faculty of Medicine

Thomas Gordon Brown

McGill University Department of Psychiatry

\section{Research}

Keywords: alcohol use, Peruvian Andes, control, responsibility, problematization, neoliberalism, ethnography, market

Posted Date: February 15th, 2021

DOI: https://doi.org/10.21203/rs.3.rs-149064/v2

License: (c) (i) This work is licensed under a Creative Commons Attribution 4.0 International License. Read Full License 


\section{Abstract}

Background Alcohol control has garnered attention from the global health community in recent years. This attention is partly prompted by increasing exposure of nefarious alcohol industry practices, coupled with the recognition that many governments have not yet put in place alcohol control policies, leaving populations vulnerable to industry influence. The Peruvian Andean highland has seen the change of the Andean practice of collective drinking in response to the increased availability of alcohol and the experience of political violence. This study seeks to merge the broader political economy with local experience and culture in order to provide a deeper understanding of the dynamic between global processes and local realities.

Methods We conducted focus group interviews $(n=19)$ with community participants, teachers, and health workers, and key informant interviews $(n=28)$. Thematic analysis identified patterns of individual and collective meaning and social, political and economic factors.

Results Local perspectives regarding loss of control over alcohol highlight the complex patterns of power and meaning exerted and experienced by different actors, shaping both understanding and behaviour. Participants' focus on parents' lack of control over alcohol use by some "abandoned" children reflects the structural vulnerability of some Andean families struggling with economic hardships. Another focus was on the money spent by men to engage in problem drinking. Participants interpreted alcohol consumption in this context as a way that men demonstrate their masculine identity and symbolic power as the breadwinner who controls the household economy. The third focus is superimposed onto the market economy. Participants expressed that the expansion of the alcohol market and perceived absence of government control coupled with macroeconomic conditions shaped patterns of alcohol consumption.

Conclusion Participants' perspectives illustrate how problem drinking is shaped not simply by an individual drinker's lack of self-control but also shaped by an environment that enables the unrestrained marketing of alcohol products and the creation of a culture of consumption. Harmful consumption is mediated by the reshaping of the Andean cultural practice of collective drinking. Attending to local perspectives is essential for policies and interventions that connect structural dynamics with the cultural and experiential aspects of alcohol consumption.

\section{Introduction}

The 2018 Global Status Report on Alcohol and Health indicates that alcohol use results in approximately 3 million deaths per year and numerous other social problems [1]. Some in the global health community suggest that alcohol remains a 'blind spot', not receiving adequate attention given the high burden on global mortality and morbidity [2]. Calls for increased attention to alcohol as a globalized health issue are supported by a growing body of research that demonstrates the aggressive approaches taken by transnational alcohol firms to expand their global market while at the same time lobbying governments to ensure minimal or no regulation of their activities $[3,4]$. The globalization of industry influence is 
propelled by the increasing consolidation of market control among large companies. For example, Jergin and Ross found that the share of the beer market held by the top 10 companies increased from one quarter in 1980 to two thirds by 2017 [5]. This context leads to concern over the growing impact of the alcohol industry, as a commercial determinant of health, in low- and middle-income countries (LMICs) [6]. While some regions like Europe have seen a decline in alcohol use, others like Africa and Asia have seen an increase in consumption [1].

The WHO's 2018 report indicates that over half of the governments in the world do not have one health protective policy in place to control the alcohol market [1]. Weak or non-existent alcohol control is sustained through industry pressure in many countries $[2,6,7]$. Local governments are also attracted by commercial alcohol revenues, inducing a tolerance for high levels of alcohol-related harm [8]. Moreover, transnational alcohol companies actively promote foreign alcohol products and increased consumption with a message of modernity and prosperity, drawing consumers away from traditional locally produced beverages [8]. As foreign alcohol products represent a new social status symbol, they also attract economically vulnerable populations. As noted, evidence suggests that promotion of transnational alcohol beverages in LMICs can alter social and cultural norms that play a role in moderating or restricting alcohol consumption [9]. This shift away from traditional norms of restraint and culturally rooted occasions of consumption combines with another shift in the framing of responsibility and control. In many LMICs, these developments have resulted in measurable increases in the volume of alcohol consumption per occasion, and the frequency and reasons for drinking [8].

What has received less attention in the literature on global alcohol control are the ways that local cultures of consumption and the meaning associated with alcohol in localized contexts intersect with global dynamics. While the emphasis on universal harms, industry practices, and best practices for alcohol control is critically important to alcohol control, there is also a need to understand how these universals intersect with local understandings and practices. This understanding can lead to a more sensitive and responsive approach to alcohol control that respects the unique ways in which global processes influence cultures of consumption, and how these cultures in turn are insulated from or respond to global processes.

The problem of harmful alcohol use has been conceptualized using different points of emphasis and epistemic frameworks specific to the time and culture $[10,11]$. For instance, during the late $18^{\text {th }}$ to mid$19^{\text {th }}$ century in the US, where the temperance movement emerged, alcohol became problematized as a transgression of personal self-control, independence, and productivity $[10,12,13]$. In the current era where neoliberal rationality both dominates and creates contradictions in the relationship between market, state and society [14], the aim of moderate alcohol consumption and self-control over drinking fostered by public health actors sits in tension with the perceived economic benefits of excessive consumption for the industry and state. Both examples illustrate that responsibility and control are often located in the individual drinker $[11,15]$. Neoliberal rationality is a mode of governing that aspires to produce selfregulating citizens [16]. This mode of governing also releases government from making value judgements about the personal and community consequences of alcohol supply on consumers; alcohol 
is viewed as a neutral economic commodity like others [17]. In this context, the neoliberal discourse stresses individual health management by self-control rather than market regulation to promote healthy choices, thus producing moral narratives of personal responsibility and blame [11, 15, 18-21]. Individuals showing drinking patterns that are considered harmful to their health and society at large are characterized as irrational and weak. Consequently, the trope of "lack of control" gives a means of expressing power and rationality when drinking is controlled [22].

The Andean highlands of Peru have seen a change in drinking practices since the 1970s. Past ethnographic studies in this region have documented the manner in which the indigenous people traditionally celebrated frequent feasts and festivals, often involving collective intoxication [23, 24]. The ritualized framework of this form of collective drinking is believed to play a role in making intoxication both meaningful and controlled [24]. However, this framework started to weaken by the increased availability of alcohol in the 1970s. By the late 1990s, trago (distilled sugarcane mash) had largely been replaced by cheaper, more accessible and concentrated alcoholic drinks [24]. In parallel, greater access to cash and credit turned occasional drinking into a routine behaviour.

Some attribute the rise in alcohol consumption to the government's failure to stimulate economic development through the Agrarian Reform [24]. From this perspective, increased consumption among economically vulnerable rural campesinos (peasants) represents a means of coping with frustration and disillusionment as a result of reduced opportunities [24]. Ritualized forms of drinking were also seen to arise from the constant fear of death during the extensive political violence from 1980 to 2000 . This period of sasachakuy tiempo (difficult times) hit the Andean region hard and appeared to shift the meaning of ritualized drinking into a mode of healing. For many in the indigenous population, this may have resulted in harmful alcohol use that persisted after the conflict ended $[25,26]$.

In Peru, these contextual factors facilitated expansion of the alcohol industry. Today, the WHO/PAHO working group recognizes the alcohol industry as a key determinant of alcohol consumption and related harms in this region and globally [6]. This group has called for policies to control alcohol consumption through a range of health information and promotion programs [27]. However, in many South American countries, policies have not yet been implemented to effectively control the expansion of the alcohol market, in part this has been attributed to the existing burden placed on health systems by persistent issues of malnutrition, sanitation, and infectious diseases [28, 29].

In light of this and other challenges, this ethnographic study integrates political economy analysis into cultural and medical anthological approaches to understand individual and community alcohol-related practices in the south-central Andean highlands of Peru. The present analysis is guided by the following questions: "What are the local perspectives on problem drinking?" and "How is the problematization of alcohol use in the community shaped by Andean cultural practices, meanings, and values associated with drinking?" In this paper, problem drinking is used to cover a range of drinking patterns that increase the risk of harmful consequences or physical and/or mental health disorders (including alcohol use disorder). By exploring the local understanding of problem drinking, this paper aims to highlight: 1) 
interactions and tensions between socio-economic structure and social processes on one hand and individual and collective meaning; and 2) how culture intersects with the power of different actors involved in production, distribution, and consumption of alcohol.

\section{Methods}

\section{Setting}

This ethnographic study was conducted in two districts in the region of Ayacucho located in the southcentral part of Peru, the Carmen Alto district and the Socos district. The Ayacucho region was the epicenter of the 20-year political violence between the communist militant group Sendero Luminoso and the state military, which resulted in the nearly 69,000 killed or "disappeared" in Peru [30]. Carmen Alto is a semi-urban district with a population of 21,350 residents adjacent to the City of Ayacucho, the capital city of the region [31]. When the violence intensified, many villagers and their families in the rural areas of the Department of Ayacucho were displaced to Carmen Alto. Peru has witnessed quite large-scale internal migration in the pursuit of better economic opportunities. Migrants account for $59 \%$ of the current district residents [31]. Residents still have limited access to water sources, sanitation facilities, and electricity [31]. The district poverty rate of $71.6 \%$ is higher than the regional poverty rate of $62.6 \%$ [31]. Today $74 \%$ of the Carmen Alto population are Catholic and $26 \%$ are Evangelical whose doctrine prohibits alcohol use. Carmen Alto has one entertainment zone close to the district centre. Recreos are popular drinking places on weekend nights, serving food and alcoholic (and non-alcoholic) beverages day and night while bands perform live music on an open stage.

Socos is a semi-rural district where the majority of the population of 7,108 engage in subsistence farming [32]. Although 32 villagers were killed by the civil police during the political violence in 1983 and the residents suffered from the ongoing threat of violence and the property theft, most of them remained or returned after the conflict had ended [30]. Mobility and access to the capital city of the Ayacucho region $18 \mathrm{kms}$ away became easier with the increased availability of taxi service to make a 30-minute journey.

\section{Ethical oversight}

The Douglas Mental Health Institute Research Ethics Board (IUSMD-15-43) and the Cayetano Heredia Peruvian University Institutional Ethics Committee (66752) provided ethics approval and oversight of the study protocol.

\section{Participant recruitment and final sample}


I (first author SY) collected qualitative data using key informant interviews, focus group discussions and participant observation throughout the fieldwork (July-November 2016). A local research consultant, Mr. Julián Berrocal Flores (JBF), who is bilingual in Spanish and Quechua, and I carried out interviews with key informant including community members, local police officers, secondary school teachers, health workers from the nearest centro de salud (health centre), and local alcohol vendors. We approached local police stations, secondary schools, and health centers of the study sites to recruit interview participants. Our inquiries at the municipality level identified potential interview participants who were knowledgeable in the history and socio-economic characteristics and traditions of the district. Table 1 describes the background of the final 28 interview participants (Socos $n=12$, Carmen Alto $n=16$ ).

\section{Table 1 Number, role and provenance of interview participants}

Community informants

Local police officers/security officers

Secondary school teachers

Health professionals

Alcohol vendors/chicha (traditional fermented corn beer) producers

Total

\begin{tabular}{|c|c|c|c|c|}
\cline { 2 - 5 } \multicolumn{2}{c|}{ Socos } & \multicolumn{2}{c|}{ Carmen Alto } \\
\hline Male & Female & Male & Female \\
\hline 2 & 3 & 2 & 2 \\
\hline 0 & 0 & 2 & 2 \\
\hline 1 & 1 & 1 & 1 \\
\hline 1 & 1 & 1 & 2 \\
\hline 1 & 2 & 1 & 2 \\
\hline & 5 & 7 & 7 & 9 \\
\hline
\end{tabular}

*Socos had no police services (i.e., no recruitment of police officers/security officers). In order to recruit focus group participants, we contacted secondary schools, health centers, and the leaders of established community-based organizations (Mothers' Club, neighbourhood council, sports teams) in Carmen Alto and a group of community health promoters in Socos. Table 2 describes the breakdown of 19 focus group discussions. On average, eight participants per group took part in discussions (Total 148 participants: Carmen Alto female=43, male $=24$, Socos female=42, male=39). We used interview guides that probed participants' views on common drinking practices and related cultural and social values, and current health and social issues seen in each district. Both key informant interviews and focus groups lasted between 30 minutes and 1.5 hours.

\section{Table 2 Number of focus groups by participant type and location}

\begin{tabular}{|l|c|c|}
\hline \multicolumn{1}{|c|}{ Group } & Socos & Carmen Alto \\
\hline Secondary school teachers & 1 & 1 \\
\hline Health professionals & 2 & 1 \\
\hline Community participants (male) & 3 & 2 \\
\hline Community participants (female) & 3 & 4 \\
\hline Community participants (mixed) & 0 & 2 \\
\hline Total & 9 & 10 \\
\hline
\end{tabular}

Prior to each focus group and interview, JBF first asked study candidates what language they preferred, and verbally explained the study purpose and the activity content, confidentiality issues including data management, participants' freedom to withdraw at any time, and compensation. Once study candidates agreed to participate and understood that interviews and focus groups would be audio-recorded, they 
were asked to provide their consent either in written or verbal form. Participants received compensation consisting of a package of food or stationery at the end of the activity.

I conducted participant observation through taking fieldnotes of daily communications with local people, and observations of daily activities and local customs, cultural/religious events, and drinking venues such as recreos on weekends throughout the eight-month fieldwork. I also participated in cultural practices by drinking, eating, and dancing with people at fiesta patronal and fiesta de agua in Socos, my neighbors and JBF's family members during birthdays and community festivals. This participant observation contributed to building rapport with community members in a cultural context where alcohol use fosters relatedness. It also helped interpretation of drinking behaviours on some occasions in a way that would not have been immediately obvious otherwise.

\section{Translation of materials}

The self-identification of the Ayacucho population is 81.2\% Quechua [33]. Hence, the back-translation method established the cultural and linguistic validity of materials employed. The bilingual research consultant (Spanish-Quechua), JBF, first translated the Spanish versions of all interview guides to Quechua. Another bilingual translator conducted back translation to Spanish, then JBF, the translator, and four local bilingual volunteers checked semantic, technical, and content equivalence between versions [34]. Discrepancies between the original Spanish and the back-translated Spanish items were discussed until agreement on the equivalent Quechua version was reached. Before starting data collection activities, we asked the participants the language they preferred. In Carmen Alto, participants chose between Spanish or mixed Spanish and Quechua as is typical in their daily lives. In Socos, Quechua was the primary choice of participants, except for the health professionals and high school teachers who chose Spanish.

\section{Analysis}

The recordings of verbatims were transcribed and analyzed in Spanish. For verbatims collected in Quechua, transcribed data were translated into Spanish. Thematic analysis was used to identify patterns of meaning or themes within the data. The thematic analysis was guided by the approach of Braun and Clarke [35], which involves an iterative process of reading transcripts, deductive and inductive coding, categorizing of codes, engaging with the literature, and further reviewing and refining coding scheme [36, 37].

Qualitative data analysis software Atlas ti®8.4.24 was used to manage and organize the data. During the analysis, I consulted with JBF to examine the cultural salience of alcohol-related values highlighted in the interviews and to make sense of observed behaviours within the historical and socio-cultural context of the south-central Peruvian Andean highlands. Some preliminary findings were shared with community participants in 2017 and 2019 in order to validate my interpretations of their accounts.

\section{Results}


"No hay control" ("There is no control") was the expression that many participants used to describe problem drinking in the community. On one hand, participants presented the perceived benefit of controlled alcohol use, such as enhancing social interaction by putting away vergüenza (embarrassment), temor (fear), and miedo (fear) and facilitating talk, sing, and dance, giving the feeling of warmness and energy in the cold harsh Andean environment, and motivating day laborers to accomplish physically demanding work in the chacra (field) effectively. Likewise, alcohol is seen as an enhancer of achieving a certain objective in negotiations as well. Offering alcohol in discussions was explained as symbolic presentation of sincerity, trust, and commitment to build close relationships, and believed to facilitate the negotiation of important issues in business and marriage.

On the other hand, participants expressed that alcohol use involving borrachera (intoxication) was problematic, while designating drinking as costumbre (habit, custom) in everyday life. Lack of control over behaviour stemming from acute intoxication was tied to individual health consequences and family and social problems, such as family conflict and separation, violence, sexual abuse, and unwanted adolescent pregnancy. While stressing the need to address these negative consequences, participants made multiple references to absence of control at multiple levels.

\section{Parents' lack of control over their children's alcohol use}

When asked about the general alcohol use in the community, the majority of participants raised concerns over adolescent alcohol use that was being initiated before the legal drinking age of 18 years old. Participants repeatedly stated that "children are abandoned," attributing underage drinking to a lack of parental control and supervision. Others said that children drink with friends in an attempt to create a substitute family situation to counteract feelings of loneliness and absence of parental emotional support.

Many participants from Carmen Alto explained that this precarious family environment was due to children are relocated to urban areas for the purpose of education while their parents remain in rural areas. Relocation of children for education in Socos is not as common as in Carmen Alto. In Socos, parents often embark on short-term travel to the selva (the Amazonian jungle) or to other cities to earn money to meet household economic needs. The children then live with relatives such as cousins and grandparents. During my fieldwork in 2016, a 15-year-old girl died after being sexually and physically assaulted by several intoxicated adolescents at a party in a neighbouring district. The assault occurred in a house with no adult supervision or presence. This incident was often mentioned as an example of how children are placed in an insecure situation without parental care, supervision, or control. During one focus group in Carmen Alto, participants described this context:

P6: It has been an invasion [of land], parents have come [as] they wanted to occupy a plot of land, and they have brought their children. They brought their kids here so that the kids can study. And then parents are in chacra (field). Who is going to control this kid?

P7: No one. 
P5: When a friend comes, and then they go to drink.

P4: They go to fiesta, and then they drink.

P5: Disco.

P6: This largely happens in this community.

(Carmen Alto, female, focus group)

Persistent economic hardship forces parents to work long hours, which results in separating parents from children and/or limiting their time with children. One 48-year-old female focus group participant from Carmen Alto stated: "I have seen mother and father are dedicated to chacra (plot of land). They are gone at 4 o'clock in the morning because of the lack of an economy".

Participants further stated that, compared with their own upbringing, parents are having a hard time controlling their children. They recalled that their parents and elders played a role in disciplining them when they were children. With punishment using chicote (whip) that is considered as useful to "give good orientation" (Socos, male, age 71, interviewee), parents and elders used this approach to inculcate obedience and respect in the hierarchical family environment.

When it comes to parental control of children's alcohol use, study participants reported that children were today becoming "rebellious and dominate their parents" (Carmen Alto, obstetrician, interviewee) by misusing their understanding of human rights and knowledge of institutional protection. "Parents were previously stricter and never let children go out in the night" (Carmen Alto, male, age 20, focus group). Most participants still largely considered the chicote as an effective and acceptable disciplinary tool. In this context, "DEMUNA" and "law" were frequently cited as barriers for parents to control their children's alcohol use. DEMUNA (the Municipal Office of the Ombudsperson for Children and Adolescents (Defensoría Municipal del Niño, Niña y Adolescente) was established in 1993 to promote and protect the rights of children and adolescents. It has the responsibility to intervene any time the human rights of children and adolescents are violated. In addition, in December 2015, Peru adopted a law prohibiting the use of physical and other humiliating punishment with children and adolescents (No 30403 "Ley que prohibe el uso del castigo físico y humillante contra los niños, niñas y adolescents"). The law, social services, and intervention by DEMUNA to protect women and children from violence were largely appreciated. A 60-year-old female focus group participant in Socos stated: "Now the law prevents men from hitting women". At the same time, others see some parents having difficulty controlling their children's misbehavior because the parents fear that their children will report them to DEMUNA, claiming that their parents' discipline is an abuse of children's rights.

"I think now we cannot pressure children. They drink and say "IIf] you say something, then I am going to report you [to DEMUNA]' and mother has this fear of being accused." 
(Socos, nurse, interviewee)

\section{Drinkers' lack of control over themselves}

Men's problem drinking explained by machismo. Lack of control was also mentioned to describe the way adult drinkers consume alcohol. A female nurse in Carmen Alto stated that "There is no control of oneself" while describing drinkers lying asleep on the street and family members suffering from harmful alcohol use. Lack of control is applied not only to chronic dependence on alcohol but also to an acute bought of heavy drinking that leads to intoxication being seen at community fiestas and social gatherings with family, friends, and co-workers on the weekend, and which often continue until dawn. As many male focus group participants in Socos described, men "drink excessively without controlling themselves", which leads to their expressing their problems, crying, or becoming aggressive, sometimes to the point of violence. The gendered division of labor in the family in relation to drinking seemed to excuse men's lack of control over their alcohol consumption. Young male focus group participants from Carmen Alto considered that married women with children drink less than single women because the former are responsible for taking care of children. During my fieldwork, I frequently witnessed women drinking with men during community fiestas, family gatherings, as well as in recreo. Nevertheless, most women consumed only a small amount of alcohol and often left earlier than men, suggesting that their alcohol use, while frequent, is distinct from that of the men. Female intoxication is largely frowned upon, as a nurse in Socos stated: "We see men being borracho (intoxicated) but seeing some women borracha is bad." With this cultural norm, a 60-year-old female focus group participant in Socos mentioned, "some couples drink together and the wife needs to control herself".

Many participants referred to the cultural concept of machismo to explain "little control with respect to male drinkers" (Carmen Alto, psychologist, interviewee). Machismo was generally cited to describe gender inequality in current everyday life. When a focus is specifically on drinking, community participants, police officers, schoolteachers, and health professionals similarly defined machismo as men's justification for spending 'hard-earned money' on drinking as an entitlement from being a 'breadwinner'. The common answer to the question, "Who drinks more? Women or men?" was "The one who has more money; men." (Socos, male, age 20, focus group). Casual laborers and construction workers often go out drinking "out of happiness when they receive wages" (Socos, female, focus group). The Andean way of sharing drinks among those who are present, that is, buying two bottles in turn once the last bottle is emptied, and continuing to drink until all the money is spent or the alcohol runs out is entangled with the practice of machismo. During a bout of drinking, men show not only physical toughness by holding their alcohol but also by their ability to purchase drinks for others. The duration of one bout of drinking and the total number of drinks "depends on the money" (Carmen Alto, male, age 19, focus group) and "If you have money, you can [continue drinking] till dawn or continue" (Carmen Alto, male, age 20, focus group).

The importance of controlling one's alcohol consumption was commonly expressed by participants. A common practice among Andean individuals engaged in labor-intensive agricultural work is to drink a "minimal proportion" of alcohol to "feel motivated to continue working". In contrast, drinking a "maximum 
proportion [of alcohol] can result in economic loss" (Carmen Alto, female, age 31, focus group). One 48year-old male focus group participant in Carmen Alto stated: "If you do not control alcohol, alcohol controls you. For this reason, it is necessary to know up to what point you can drink. There are others who do not have this kind of control." On one hand, men try to exhibit control over the household economy and their health by "calculat[ing] the quantity of beer" they pour into the glass as they know that it is their turn to buy another round of drinks if they empty the bottle (Carmen Alto, male, age 50, focus group). At the same time, they know "who buys and who does not buy", as being seen as a free rider (i.e., only drinking alcohol that friends buy) has a risk of "not being invited for the next time" (Carmen Alto, male, age 50, focus group). Male participants also explained the difficulty in controlling their drinking and spending while practicing machismo, especially when competitiveness accelerates drinking. A young male focus group participant in Socos stated: "Before you become drunk, you think. When you drink, the alcohol [level] goes up, and you start losing control of yourself. You practically forget everything for the moment.... Now the experience is that while you are drunk, you could be what you wish to be without control....". Many male community participants stated that they often end up feeling regretful (arrependimiento, pesares) and guilt (culpa) the following day when they remember what they did and how much they spent on alcohol the previous night.

Facilitator: What do you do after drinking? What do you do on the following day? How do you feel and what do you do?

P3: Take a cold shower.

P12: Reflect.

Facilitator: What do you reflect on? About why you drank?

P12: Why....yeah, about what kind of things I have done. I remember, maybe I may have done something bad or I was not respectful to someone, or maybe, I misbehaved, how many cases I drank.

P1: How much I spent.

P12: How much I spent.

Interviewer: Yes, like damaging the economy of your family?

P12: Yeah, I analyze whether I have damaged, maybe...[whether] I drank for free while friends spent all the money.

(Socos, male, focus group)

Men's spending on alcohol and notions of responsibility. The apparent lack of control in men's drinking reflects not only excessive alcohol use but also men's identity-making and power representation in public and domestic spaces. In the domestic space, men's spending money on alcohol was criticized for the negative impact it had on the household economy. It was noted that this type of spending could lead 
to conflict between spouses. Some female participants showed their frustration with their husbands' spending on alcohol by describing that "It is worse when a drunken husband responds, 'I do not drink with your money"' (Socos, female, age 48 , focus group).

Health workers and high school teachers often cited the concept of "cultura etílica", which expresses an individual's responsible drinking and self-control based on the awareness of the amount of alcohol they can manage and still fulfill their social and employment responsibilities. A psychologist explained that cultura etílica is "control, [with awareness that] I am drunk and I can cause some problem because I know how I am," unlike "others [who] have many responsibilities the next day and know how they are but they do not control" (Carmen Alto, psychologist, focus group). Among community participants, it is also commonly understood that people "should drink rationally (racionalmente) only up to the point [they] can afford" (Carmen Alto, male, age 48, focus group).

P5: Instead of spending money on alcohol, it is better to eat.

P4: It is better to eat no matter how little.

P6: You should fill yourself up with 100 Soles, not with beer.

P4: Sometimes we spend in vain.

Julián: Spending in vein

P3: When we are drinking with friends, we challenge ourselves. And then we use our money and nothing remains for our wife.

(Socos, male, focus group)

Some men are reported to spend a disproportionate amount of money on alcohol, often to the point of spending all received wages during a weekend or life savings at a fiesta patronal, even though both they and their spouses work to cover household expenses. While participants often joked that "people work to drink" in Ayacucho (Socos, male, age 21, focus group), spending earnings on alcohol rather than on household expenses as a demonstration of manliness was questioned and considered a lack of responsibility. A high school teacher in Socos described some parents' attitude thusly: "There are people who do not have money to buy food for their child. [But they have money] to buy 5 cases of beer and drink all the night." Some community participants particularly evangelists, health professionals, and high school teachers characterized men's spending on alcohol consumption to be reckless extravagance in contradiction with the economic situation of Ayacucho where some "children are still without bread" (Socos, male, age 63, focus group).

\section{Lack of control over alcohol supply}


Expansion of the alcohol market by increased advertising, promotion, and availability. Participants also noted the normalization of drinking described as costumbre (custom, habit), which was attributed to the lack of control over the expanding alcohol market. One young male focus group participant in Socos described it by stating: "If you leave [home], you see people drinking on the street, [and] at the corner. There is no respect...At one corner, you see one fiesta, and at another corner, you see another." The easy availability of alcohol has also shaped drinking practices in the community. While the traditional community fiestas still play a role in strengthening social relations through the practice of Andean reciprocal support, ayni, many participants no longer attributed to fiestas the values and meanings that they once held. For instance, a schoolteacher in Carmen Alto stated:

[Traditional] fiesta is commercial. Now it is already a commercial activity because now everything is about selling. For example, I see people want to make money, profit in the fiesta patronal...Yes, it used to be something cultural, but in the past few years, it is not any longer. The economic aspect is added. Profit.

(Carmen Alto, schoolteacher, focus group)

Many community participants shared this sentiment. One elderly male participant in Socos described the organizing of traditional fiestas of Catholic Saints as being costlier as it becomes "more modern", stating that nowadays, "Only the one who has money can be mayordomo (host of the community festival)," who "takes the responsibility [of hosting the fiesta] with money with caprice [not with faith]" (Socos, male, age 71 , interviewee).

On one hand, in resource-scarce rural settings in the Andean highlands like Socos, community fiestas with collective drinking are still considered to be a practical mechanism to sustain subsistence living by strengthening and maintaining the bond of relatedness among family and community members. One 50year-old female focus group participant in Socos stated: "In techada de casa (house building), we help each other and drink and dance, this is how we build casa (house). In techada de casa, we become close to each other, drink, if we do not do it, there is nothing."

Participants in both districts often compared the availability of alcohol to staple food. As one stated: "Bread can run out, but beer is always [available] at each store, it is ever-present" (Carmen Alto, female, age 43 , focus group). In addition, participants in both districts noted the increase in drinking venues such as recreo and events such as festivals and music concerts, the improved road conditions and accessibility of transportation between Ayacucho and Socos, and the availability of low-cost alcoholic beverages mixed often with soda drinks.

Participants described the expansion of the local alcohol market by saying: "Beer is a gold mine", and "Everyone now wants to open his cantina (bar) all over the world" (Carmen Alto, male, age 20, focus group). Despite the poor economic conditions, alcohol is affordable and accessible. This includes caña (sugarcane alcohol) and trago (alcohol), which are thought to make people drunk rapidly and be harmful to health. One nurse in Socos stated: "caña damages our brain more and [it is better] to choose 
beer." These types of alcohol can be easily found at local vendors who also sell alcohol on credit to regular customers, facilitating access even to those who have limited resources. The diversification of alcoholic beverages was also noticeable; as one 43-year-old female focus group participant from Carmen Alto stated: "Now those businesses are innovating that theme of beer. Now there is beer made of quinua (quinoa) and trigo (grain)". Also, when I returned to Ayacucho in March 2019, I saw Budweiser, which had become available in the Peruvian market in 2017 [38], being sold for the first time during Carnival. Such global beer brands sold by the Peruvian brewery Backus-Budweiser, Corona, and Stella Artois-are reported to have increased in volume by $73 \%$ and resulted in a $63 \%$ increase in profit in 2018 from the previous year [39].

Participants often stressed how advertising by alcoholic beverage companies and media created demand for alcohol. There are no legally binding regulations on alcohol advertising or sales promotion in Peru [1]. Participants often explained the perceived increase in alcohol use among adolescents and women as due to the influence of advertising through a wide range of media.

P10: And the advertisement also influences a lot. For example, on TV, we see young girls drinking, right? In the TV commercial, we see women drinking...

P3: In the advertisement, we see girls drunk and you think that they are cute.

P10: There are women and young girls who are becoming like that. Those women also buy beer to drink with men.

(Socos, health professional, focus group)

An advertisement for Pilsen beer that proclaims "Thursday is a day of buddies" [Jueves de Patas] is another frequently cited example. Participants were conscious that this was a marketing strategy to add an occasion to drink during the week, as drinking on the weekend with colleagues, friends, and family members is already an established drinking practice.

P5: Cheap alcohol drinks that do not even have any brand or any registration, I think, need to come from the top [government] to avoid [unofficial] factories of those alcohol. We need to cut these alcoholic beverages. Up to now they do advertisement for "Jueves de Patas" (Thursday for buddies) and "Viernes de Amigos" (Friday for friends).

P7: Fathers' day, Friends' day, everything [about drinking is] everywhere in the city.

P6: From the same manufacturer. Jueves patita ha ha ha ...

P5: Because everything about this is to motivate drinking.

(Socos, high school teachers, focus group) 
With the felt impact on alcohol availability, the alcohol industry is blamed for creating alcohol-related problems in the community while making profits off of consumption. Participants repeatedly mentioned Peru's largest brewery, Backus, which became part of the international AB Inbev group after its fusion with SABMiller group in 2016 [40]. Participants see Backus as making huge profits: "[Alcohol] business is making millionaires, Backus is a millionaire" (Carmen Alto, male, age 20, focus group).

Capitalizing on vulnerability. In parallel with excessive alcohol use at community fiestas and weekend social gatherings, participants expressed that alcohol use can be a means of coping with psychological distress for "some [who] do not know how to manage problem and seek alcohol" and "think that they can solve problems while being drunk" (Carmen Alto, male, age 20, focus group). They described solitary drinkers-those who drink as a means of coping with hardships such as family conflict, financial concern, and breakup who gradually develop alcoholismo (alcoholism). Some participants suggested that the alcohol companies take advantage of this vulnerability to pursue profits. Community participants framed problem drinking as the result of market forces that push the rural poor unable to find a solution to their problems to consume alcohol.

Previously, possibly in the 80 s and 70 s, here in our community, people used to celebrate, organize activities with the purpose of reevaluating our costumbres (customs, habits). Day by day, they do not organize fiestas with this purpose. We do fiestas with the purpose of getting people to consume alcohol, and this is the purpose of business. Those who benefit are only big business. How much revenue do we generate for Backus? Whatever quantity, people like, people like to organize fiestas, every weekend, fiesta in Arenales, [fiesta] in San Luis, now for the Day of All Saints. We have a number of fiestas. Then, those businesses benefit, and we do harm to ourselves, people in the rural area. People who are not prepared. People who cannot solve their problems dedicate themselves to alcohol. "I drink to take refuge in alcohol" [they say]." (Socos, male, focus group)

The active promotion of alcohol for economic gain was contrasted with the economic hardships and precarity of those who were consuming alcohol. This sentiment was summarized by one participant, who stated: "Some people who have economic problems take refuge in alcohol even though they do not have [money] to buy other types of things" (Socos, health professional, focus group).

Absence of Government Control. Alcohol sales have been increasing in Peru, exemplified by a $24.6 \%$ increase in Backus's sales of beer from 2012 (S./3,160.2 mil) to 2017 (S./3,939.0 mil) [38, 41]. Community participants often blamed the local government for not tightly controlling the sale of alcohol to minors or the sale of clandestine alcohol beverages, and for not limiting the hours of the day when alcohol is sold. While witnessing alcohólicos who use alcohol as a means of coping with personal misfortune and misery, some community participants continue to blame the government. A female focus group participant in Carmen Alto stated: 
An alcohólico doesn't seem to become alcoholic because he wanted to, but there are reasons. They can be infidelity, others can be a factor related to work, lack of economic resources, and if he has a family, the more he drinks, the more fights [due to] the consumption of alcohol...Yes, the authorities are to be blamed for allowing stores to sell alcohol...there is ethyl alcohol which they sell, mixed with water, and that is what causes them to become ill, and that really gives me pena (sadness), when I see an alcohólico...

Participants perceive this seeming expansion of the alcohol market as tied to the unwillingness of the government to control it.

With this drinking including [drinking by] minors, when people drink, there is more revenue for the government because of more consumption. Although people say there would be pills, medication [for addiction], the government will not approve it because there is more revenue for the government wherever there is a factory for alcohol, or even coca. For this reason, drinking will not disappear.

(Socos, male, age 54 , focus group)

The local government collects tax from flourishing business activities in the entertainment zone of Carmen Alto. One Saturday night in Carmen Alto, I saw many women opening street stalls in front of bars and recreo to sell food to hungry drinkers, while paying the municipality some monthly fee to use the street for their business. Community participants in Carmen Alto partly attributed the seeming reluctance of the local government to control local alcohol sale to its alleged motive of keeping the tax revenue from the alcohol consumption and related business activities.

\section{Discussion}

The local perspectives described above highlight the complex patterns of power and meaning exerted and experienced by different actors at different levels, and which shape behaviour and local understanding regarding loss of control over alcohol. Many of these sites of control have shifted dramatically with the globalization of markets and cultures, and the influence of transnational alcohol companies. Excessive alcohol use can be seen as a failure in self-management that subjects the drinker to stigma and social marginalization $[15,18]$. However, scholars in critical medical anthropology often position alcohol use in relation to social suffering created by macrolevel structures and relations of power such as socio-economic inequalities, systemic discrimination, and dominant corporate institutions [42, 43]. Echoing this political economy perspective, community participants expressed how problem drinking is shaped not simply by an individual drinker's lack of self-control but also by an environment that enables the unrestrained promotion, advertising and marketing of alcohol products and the fostering of a culture of consumption. Furthermore, the Andean cultural practice of collective drinking mediates the rise of problem drinking. In part, this analysis demonstrates that the meaningfulness of this practice has shifted towards more regular collective drinking that is not tied to historically meaningful events, celebrations or functions. Alcohol use is increasingly tied to political economic interests that seek to promote increased consumption. 
Participants' perspectives on parents' lack of control over alcohol use by some "abandoned" children reveals structural vulnerability in which Andean families are "positioned socially in an inferior status within a prevailing social order by virtue of one's social status and life conditions" [44]. The Quechua's collective well-being, "sumaq kawsay," is shaped through cohabitation by accumulating mutual trust, help, and respect among family and community members [45]. However, due to persistent poverty, some parents and children have to be separated, which limits the shared family time and space to cultivate collective well-being. Economic hardships in the Andean highlands persist, with the socio-economic inequality between the highlands (33.3\% poverty rate) and the coast $(14.3 \%)$ [46]. In this context, parents are using the available resources not only to meet immediate family needs but also to invest in children's education in order to help the children access other economic opportunities [47]. Although relocating young children to live in a new household of relatives is an established Andean cultural practice, participants provided cases where children do not receive sufficient care, attention, or affection necessary for healthy physical and psychological development [48-50].

In addition, precarious family relations may detract from parents' control over children's alcohol use. Because of parents' migration and/or children's relocation, building family trust and bonds can become difficult. In this situation, the knowledge that children acquire through education about their rights and the institutional instruments to protect these rights seems to have an unintended effect on the traditional mode of discipline, in which parents would control children's misconduct. The child protections from the state are enmeshed with these shifts in family composition, connectedness and the added pressures of economic precarity.

Another common perspective about lack of control relates to the cultural concept of machismo. While the definition varies, machismo is generally associated with competition against other males and the expression of 'masculine' norms [51, 52]. Being macho is typically presented through an ability to drink alcoholic beverages in large quantities without giving in to the effect of intoxication [51]. Likewise, men's heavy episodic drinking is a common drinking pattern, as $90.5 \%$ of male drinkers in Ayacucho are found to consume five or more drinks at one or more occasions, compared with $74.0 \%$ in Lima [53]. Work allows men to demonstrate their manhood symbolically by not only providing for the basic needs of their families, but also by participating in the gatherings where alcohol is consumed [52]. While the qualities associated with manliness relate to both public work and domestic life spheres, in the public arena, characterized by competitiveness and rivalry, peer pressure usually drives men to spend more money than initially planned on alcohol to validate their own masculinity [52].

Men's drinking pattern is also bound up with their own sense of lack of control over either their feelings or the culture of collective drinking in which they feel the need to participate. Some drinkers were described as using alcohol to cope with daily struggles such as family problems and financial problems. Not being able to fulfill the traditional role of breadwinner or to exercise masculinity due to poverty is a source of frustration among Andean men in Peru, leading to family disputes [54]. In this context, spending hardearned money on alcohol-while at the same time showing the ability to control the household economyappears to involve drinkers' agency in controlling their emotional distress and achieving cultural values. 
In Ayacucho, particularly in rural areas like Socos, many families are supported by the government cash transfer program (Programa Juntos). As seen in many LMICs [55], a father's spending money on alcohol that leaves little to nothing for household needs can create a chronic financial burden on the family. In Guatemala and Colombia, this is identified as an economic hardship within the urban poor households, while problem drinking is associated with indebtedness within communities [56]. The availability of cheap clandestine alcohol and credit exacerbates the vicious cycle involving poverty, uncontrolled alcohol use and addiction [56].

The focus of health workers and schoolteachers on a man's individual management and control of alcohol consumption can produce moralistic narratives of personal responsibility and blame in a modern society $[19,57]$. However, the primary focus on a lack of individual responsibility and control can relegate other socio-cultural determinants entangled with individual and collective drinking, such as poverty, education, and the physical environment, to the background $[58,59]$.

As negative consequences of alcohol use have become visible, the focus of the participants' perspectives about lack of control is superimposed onto the market economy. As participants' accounts suggest, the growing alcohol market has reshaped Andean drinking practices, resulting in reported negative consequences. When drinking occasions were limited to traditional fiestas based on Andean agricultural cycles and the religious calendar, they were valuable opportunities for sustaining the safety net of reciprocity in goods and services among one's fellows. Today, collective drinking is a part of Andean daily life as community participants often described: "When someone wants to drink, there is no lack of motive" and "Today anything can be a motive for drinking" (Carmen Alto, female, age 43, focus group).

Participants' recurrent references to Backus, the largest brewery in Peru, indicate the degree of its visibility and influence. SAB-Miller-one of the top international brewing companies to which Backus once belonged-ranks among the top 10 largest advertisers in Peru [3]. Community participants are witnessing and experiencing how the alcohol industry is profiting from existing norms of collective drinking. Meanwhile, the local government does not appear to be prepared to actively control the sale of alcohol due to the revenue from alcohol consumption and related businesses. At a macro level, the dominant neoliberal paradigm has shaped how government, either directly or indirectly, influences the supply of alcohol in a global market system [17]. While people often overlook "commercial determinants" of alcohol consumption, the alcohol industry's aggressive marketing in many LMICs can exploit the poor legislation and regulations and to shape people's drinking patterns and behaviours $[2,6,7]$. For instance, Backus launched a campaign of "responsible drinking" in 2018 during Semana Santa (Holy Week), a traditional religious event for drinking during consecutive days [60]. However, research suggests that responsible drinking messages remain strategically ambiguous to meet both the industry's interest in sales and public relations [61]. In this context, the notion that "alcoholismo is a social illness," as stated by a schoolteacher, brings attention to the market, social, and governance forces that can contribute to alcohol-related illnesses that also stigmatize and isolate drinkers.

\section{Strengths And Limitations}


The political economy approach adopted in the study unpacked complex macro-micro interactions and power dynamics that constantly shape the meaning and practice of alcohol use in the south-central Andean highlands of Peru. A major limitation of the current study is one of scope, namely the limited exploration of the role of religion in the popular perspective on control. In the Andean highlands, evangelical churches associate alcohol use with backwardness, laziness, and lack of self-control, while playing a role of healing site of a range of illnesses including alcoholismo [62, 63]. In both study sites, evangelism that prohibits the consumption of alcohol has had a growing influence on community activities since the political violence took place [64]. In focus group discussions, evangelistic community members shared their experiences-such as having a drinking problem before conversion from Catholicism, or having no experience of drinking alcohol-while stressing how abstinence can avert the negative consequences of alcohol consumption. Likewise, evangelists are sometimes seen as "criticizing those [Catholic residents] who drink alcohol and cause problems" (Socos, male, age 60, focus group). With this potential tension between Catholic and evangelist participants, the presence of Catholic community members in the focus group may have inhibited evangelistic participants from generating a distinct faith-based perspective on control.

In addition, because this study focused specifically on drawing data from observation and interviews with an emphasis on culture and personal perspectives and experiences, the market and government landscapes were not investigated in-depth. Further policy and political economy analysis would strengthen the understanding of policy and market dynamics pertaining to alcohol marketing and regulation.

Furthermore, female participants might have had difficulty sharing their perspectives on and experiences of alcohol use with other participants and/or research team members. While male and female participants were separated during focus group discussion, the existing cultural norm that female alcohol use outside of community fiestas and family gatherings is not widely acceptable, particularly in Socos, may have constrained the access to the full range of female participants' accounts. The cultural significance of female alcohol use and its impact on power relations and family dynamics in the present research setting and other LMICs could be deepened in future studies.

\section{Conclusion}

In this paper, local perspectives of (lack of) control reveals the ways in which problem drinking is shaped by different layers of power held by a range of individuals and institutions that constantly interact with each other and actively produces new identities and values. A few implications are drawn in response to a local call for prevention of and intervention in problem drinking. First, attention should be paid to the underlying challenging socio-economic daily living conditions of the Peruvian Andean highland population, where "social forces beyond the control of individuals influence and constrain personal choices and decisions, which are often misperceived as willful behavior and moral irresponsibility" [44]. Household expenditures on alcohol can exacerbate poverty, and community development can be hampered by diverting scarce resources to respond to the negative social and health effects of alcohol 
use [61]. In this context, community-level interventions supporting access to improved economic opportunities should accompany health policy and interventions.

In addition, the voices of community members need to be incorporated into the local action for preventing harmful alcohol use. A challenging political environment reflects participants' frustration with the expanding alcohol market as well as the unwillingness of the local government to constrain it. In addition, in the Andean socio-cultural context, where collective drinking has its own cultural meanings and social values, the change needs to be driven by people in the community. One psychologist in Carmen Alto stated: "Change or interven[ing] [is difficult] because this is very much a theme of culture or socio-cultural. It is ingrained... To say people 'Do not do' is like [saying] 'Stop being Peruvian. Be Chilean."' Within this context, attending to community voices is essential for policies and interventions that connect structural dynamics with the cultural and experiential aspects of alcohol consumption.

\section{Declarations}

\section{Authors' contributions}

SY led the study design, data collection, analysis and writing of the manuscript. RL and TB contributed to the discussions and critical review upon which this manuscript is based, and to the PhD supervision of SY. All authors read and approved the final manuscript.

\section{Funding}

This research was funded by Mary A. Metcalf International Travel Fund in Global Health Program and the Duncan Pedersen Award in Global Mental Health Program, McGill University and research grants from the Japan Osler Society and Uehiro Foundation on Ethics \& Education.

\section{Acknowledgements}

Our appreciation goes to the participants and Mr. Julián Berrocal Flores for their contribution to the study.

\section{Availability of data and materials}

The data from interviews are available from the corresponding author on reasonable request

\section{Ethics approval and consent to participate}

The Douglas Mental Health Institute Research Ethics Board (IUSMD-15-43) and the Cayetano Heredia Peruvian University Institutional Ethics Committee (66752) provided ethics approval.

\section{Consent for publication}

Not applicable. 


\section{Competing interests}

The authors declare that they have no competing interests.

\section{References}

1. World Health Organization. Global status report on alcohol and health 2018: World Health Organization; 2019.

2. Marten R, Amul GGH, Casswell S. Alcohol: global health's blind spot. The Lancet Global Health. 2020;8(3):e329-e30.

3. Jernigan DH. The global alcohol industry: an overview. Addiction. 2009;104:6-12.

4. Miller D, Harkins C. Corporate strategy, corporate capture: Food and alcohol industry lobbying and public health. Crit Soc Policy. 2010;30(4):564-89.

5. Jernigan D, Ross CS. The alcohol marketing landscape: alcohol industry size, structure, strategies, and public health responses. Journal of Studies on Alcohol and Drugs, Supplement. 2020(s19):1325.

6. Walls H, Cook S, Matzopoulos R, London L. Advancing alcohol research in low-income and middleincome countries: a global alcohol environment framework. BMJ global health. 2020;5(4):e001958.

7. Delobelle P. Big Tobacco, Alcohol, and Food and NCDs in LMICs: An Inconvenient Truth and Call to Action: Comment on" Addressing NCDs: Challenges From Industry Market Promotion and Interferences". International journal of health policy and management. 2019;8(12):727.

8. Schmidt LA, Room R. Alcohol and inequity in the process of development: Contributions from ethnographic research. The International Journal of Alcohol and Drug Research. 2012;1(1):41-55.

9. Room R, Jernigan $D$. The ambiguous role of alcohol in economic and social development. Addiction. 2000;95(12s4):523-35.

10. Garriott W, Raikhel E. Addiction in the Making. Annual Review of Anthropology. 2015;44:477-91.

11. Reith G. Consumption and its discontents: Addiction, identity and the problems of freedom. The British journal of sociology. 2004;55(2):283-300.

12. Raikhel E. 15 From the Brain Disease Model to Ecologies of Addiction. Re-visioning psychiatry: Cultural phenomenology, critical neuroscience, and global mental health. 2015;375.

13. Room R. The culture framing of addiction. Janus Head. 2003;6(2):221-34.

14. Foucault M. The birth of biopolitics : lectures at the Collège de France, 1978-79. Houndmills, Basingstoke, Hampshire [United Kingdom] ;: Palgrave Macmillan; 2008.

15. Room R. Addiction and personal responsibility as solutions to the contradictions of neoliberal consumerism. Critical Public Health. 2011;21(2):141-51.

16. Rose N. Powers of freedom: Reframing political thought: Cambridge university press; 1999.

17. Lencucha R, Thow AM. How neoliberalism is shaping the supply of unhealthy commodities and what this means for NCD prevention. International journal of health policy and management. 
2019;8(9):514.

18. Room R. Stigma, social inequality and alcohol and drug use. Drug and alcohol review. 2005;24(2):143-55.

19. Phillips T, McMichael C, O’Keefe M. "We invited the disease to come to us": neoliberal public health discourse and local understanding of non-communicable disease causation in Fiji. Critical Public Health. 2018;28(5):560-72.

20. Phillips T. The Everyday Politics of Risk: Managing Diabetes in Fiji. Medical Anthropology. 2020:1-16.

21. Gowan T, Whetstone S, Andic T. Addiction, agency, and the politics of self-control: Doing harm reduction in a heroin users' group. Social Science \& Medicine. 2012;74(8):1251-60.

22. Quintero G, Nichter M. The semantics of addiction: moving beyond expert models to lay understandings. Journal of Psychoactive Drugs. 1996;28(3):219-28.

23. Dietler M. Alcohol: Anthropological/Archaeological Perspectives. Annual Review of Anthropology. 2006;35(1):229-49.

24. Allen CJ. Let's Drink Together, My Dear! Bowser JJaBJ, editor. Gainesville: University Press of Florida; 2009.

25. Theidon K. Entre prójimos: el conflicto armado interno y la política de la reconciliación en el Perú: Instituto de Estudios Peruanos; 2004.

26. Medina JM. Desplazamiento y Cambios en Salud. Ayacucho, Perú: 1980-2004. Lima: Organización Panamericana de la Salud; 2010.

27. PAHO. Experts discuss problem drinking in Peru 2019 [Available from:

https://www.paho.org/hq/index.php?option=com_content\&view=article\&id=12431:experts-discussproblem-drinking-in-peru\&ltemid=42050\&lang=en.

28. Caetano R, Laranjeira R. A 'perfect storm'in developing countries: economic growth and the alcohol industry. Addiction. 2006;101(2):149-52.

29. Esser MB, Jernigan DH. Policy approaches for regulating alcohol marketing in a global context: a public health perspective. Annual review of public health. 2018;39:385-401.

30. Transfer Commission of the Truth and Reconciliation Commission of Peru. Hatun Willakuy, Abbreviated Version of the Final Report of the Truth and Reconciliation Commission2004.

31. Municipalidad Distrital de Carmen Alto Gestión Municipal. Plan de Desarrollo Concertado del Distrito de Carmen Alto 2015-2025. Carmen Alto, Provincia Huamanga, Ayacucho, Peru2015.

32. Municipalidad Distrital de Socos. Plan de Desarrollo Concertado 2008-2020. Ayacucho, Peru2008.

33. Rojas RT. INFORME DE INVESTIGACIÓN: Importancia Estadística de la Población Peruana Quechua, Aymara y Nativa de la Amazonía, y Legislación sobre Escaños Reservados para Pueblos Originarios en América Latina. In: Departamento de Investigación y Documentación Parlamentaria, editor. Lima, Perú2018.

34. Flaherty JA, Gaviria FM, Pathak D, Mitchell T, Wintrob R, Richman JA, et al. Developing instruments for cross-cultural psychiatric research. Journal of Nervous and Mental Disease. 1988. 
35. Braun V, Clarke V. Using thematic analysis in psychology. Qualitative research in psychology. 2006;3(2):77-101.

36. Neale J. Iterative categorization (IC): a systematic technique for analysing qualitative data. Addiction. 2016;111(6):1096-106.

37. DeSantis L, Ugarriza DN. The concept of theme as used in qualitative nursing research. Western Journal of Nursing Research. 2000;22(3):351-72.

38. Backus. Memoria Anual 2017 Lima2017 [Available from: https://www.backus.pe/sites/default/files/2020-02/Memoria\%20Anual\%202017.pdf.

39. Backus. Memoria Anual 2018 Lima2018 [Available from: https://www.backus.pe/sites/default/files/2020-02/Memoria\%20Anual\%202018.pdf.

40. Backus. Memoria Anual 2016 Lima2016 [Available from: https://www.backus.pe/sites/default/files/2020-02/Memoria\%20Anual\%202016.pdf.

41. Backus. Memoria Anual 2012 Lima2012 [Available from: https://www.backus.pe/sites/default/files/2020-02/Memoria\%20Anual\%202012.pdf.

42. Singer M. Anthropology and addiction: an historical review. Addiction. 2012;107(10):1747-55.

43. Singer M. Toward a political-economy of alcoholism: the missing link in the anthropology of drinking. Social Science \& Medicine. 1986;23(2):113-30.

44. Quesada J, Hart LK, Bourgois P. Structural Vulnerability and Health: Latino Migrant Laborers in the United States. Medical Anthropology. 2011;30(4):339-62.

45. Sotelo EA. Indicadores de cambio en salud mental comunitaria de una población afectada por conflicto armado interno en Apurímac. Lima, Peru: Pontificia Universidad Católica del Perú (PUCP); 2016.

46. Instituto Nacional de Estadística e Informática. Perú: Síntesis Estadística 2015/Statistical Overview 2015. Lima, Perú2015.

47. Bebbington A, Hinojosa-Valencia L, Munoz D, Lizarazu R. Livelihoods and resource accessing in the Andes: desencuentros in theory and practice. Wellbeing in Developing Countries: from theory to research. 2007:176-98.

48. Strocka C. Unidos nos hacemos respetar: jóvenes, identidades y violencia en Ayacucho: Lima; 2008.

49. Leinaweaver JB. On moving children: the social implications of Andean child circulation. American ethnologist. 2007;34(1):163-80.

50. Leinaweaver JB. The circulation of children: Kinship, adoption, and morality in Andean Peru: Duke University Press; 2008.

51. Bolton R. Machismo in motion: The ethos of Peruvian truckers. Ethos. 1979;7(4):312-42.

52. Fuller $\mathrm{N}$. The social constitution of gender identity among Peruvian men. Men and Masculinities. 2001;3(3):316-31.

53. Graham KM. Unhappy hours: Alcohol and partner aggression in the Americas: Pan American Health Org; 2008. 
54. Rojas DC, Zagal MC. Resiliencia de adolescents frente a la violencia política en Ayacucho y Cusco. In: Bustamante Chávez IE, Rivera Holguín, M. E., \& Matos Retamozo, L. E., editor. Violencia y trauma en el Perú Desafíos y respuestas. Lima-Perú2013. p. 79-93.

55. Patel P, Kaiser BN, Meade CS, Giusto A, Ayuku D, Puffer E. Problematic alcohol use among fathers in Kenya: Poverty, people, and practices as barriers and facilitators to help acceptance. International Journal of Drug Policy. 2020;75:102576.

56. Moser CO, Mcllwaine C. Encounters with violence in Latin America: urban poor perceptions from Columbia and Guatemala: Psychology Press; 2004.

57. Petersen A, Lupton D. The new public health: Health and self in the age of risk: Sage Publications, Inc; 1996.

58. Glasgow S, Schrecker T. The double burden of neoliberalism? Noncommunicable disease policies and the global political economy of risk. Health \& place. 2016;39:204-11.

59. Savic M, Ferguson N, Manning V, Bathish R, Lubman DI. "What constitutes a 'problem'?" Producing 'alcohol problems' through online counselling encounters. International Journal of Drug Policy. 2017;46:79-89.

60. Villegas M. Semana 'Tranqui': la campaña para evitar consumo en exceso. El Comercio. 2018.

61. Casswell S, Thamarangsi T. Reducing harm from alcohol: call to action. The Lancet. 2009;373(9682):2247-57.

62. Harvey P. Gender, community and confrontation: Power relations in drunkenness in Ocongate (Southern Peru). Gender, drink and drugs. 1994:209-34.

63. Orr DM. Religious conversion and madness: contested territory in the Peruvian Andes. In: Littlewood R, Lynch R, editors. Cosmos, Gods and madmen: frameworks in the anthropologies of medicine. Berghahn: Oxford; 2016. p. 133-53.

64. Gamarra J. Conflict, Post-Conflict and Religion: Andean Responses to New Religious Movements. Journal of Southern African Studies. 2000;26(2):271-87. 